\title{
Analysis on Security of Physical Education and Training
}

\author{
Ling $\operatorname{Han}^{1}$ \\ ${ }^{1}$ Xi'an Medical University, Shannxi, Xi'an, 710021
}

KEYWORDS: Security; Physical Education; Training; Analysis

\begin{abstract}
Sports training sports teaching physical education or sports essential items, also sports the most important aspect of their sport has a profound practical interpretation "and security is a more important factor in thinking, Sports training should strengthen the security awareness training, to avoid accidents. "in addition, security measures are indispensable" in the process of conducting sports training, sports safety factors can be summed up by a long-term training, and be able to some extent, to deepen the "paper focuses on sports training, safety precautions should be commonly noted".
\end{abstract}

\section{Introduction}

In recent years, due to various subjective and objective reasons, such as: student physical decline; teachers and students lack of safety awareness; site equipment safety hazards; teacher attitude is not serious, not strong sense of responsibility; teaching skills decline and abnormal operations and other factors. In school physical education and sport, all types of injury accidents occur frequently in our midst, is a "hard to detect", carried out on school sports education is a big negative influence and impact. Coupled with the examination-oriented education due to the impact of deep content security education are excluded from normal teaching, cannot get the attention they deserve, in this case, many schools have adopted a negative precaution, PE the elimination of the high degree of difficulty and danger of larger projects shot, vaulting horse, parallel bars and other long-distance running and to avoid single sports injuries, so that will not be conducive to the overall development and improvement of physical exercise capacity of students. Therefore, how to ensure the safety of school physical education, and promote the smooth conduct of school physical education has become an important issue to be solved in school physical education. One of the important safeguards in Physical Education, PE teachers successfully complete a series of teaching tasks, that is, teaching skills to master degree. In physical education teacher only full use of good teaching skills and awareness of security in order to protect the safety of the student movement, in order to achieve the purpose of the task of teaching and school sports programs.

\section{Situation Analysis of Physical Education Safety}

The sports injury situation is not optimistic. From the survey of sports injury situation, a larger proportion of sports injuries, nearly half of the students sports injury occurred and the proportion of boys than girls significantly damage. Types of sports injuries occur mostly sprains, bruises, fractures, and bone which suffered numerous pull, pull, twist a variety of extrusion, resulting in excessive local load too heavy, easy to damage. Item of sports injuries occur more balanced, $35 \%$ occurred in track and field, 30\% occurred in sports, $25 \%$ occurred in the gymnastics classes. Sports injuries occur more concentrated period of time, $40 \%$ of students do technical action occurred in $40 \%$ of the students take place in the free practice, only $10 \%$ of students occurs when preparing 
activities, this phenomenon may be due to Warming inadequate action or technology is not in place or improper management, which leads to the occurrence of 40 percent of the students were doing the freedom of movement and technical activities. It lacks of safety education in the basic state. Safety education in the form of a single links and Physical Education Safety is not close. The grounds maintenance is not timely and facility safety inspection frequency is not high.

It mainly due to sports injuries or injuries: Main sequentially concentrated in the sports teacher, the students themselves, teaching content arrangements set unreasonable, school grounds security problems in these areas, physical education teacher can occur for Sports Injury the main reason to improve the appropriate teaching skills and take appropriate measures to reduce or avoid the occurrence of sports injuries.

The higher safety of teachers and students sports consciousness, but only stay on the surface. From the situation of sports safety awareness survey, the proportion of students and teachers have safety awareness is very high, but from a sports injury status point of view, which should cause us to ponder, sports safety awareness just stay on the surface, there is no little or countermeasures to curb PE Teaching negative phenomenon.

\section{The Cause of Sports Injuries Accident}

While physical training has a very important positive role, but during sports training, should particularly pay attention to security. Currently, training in sports there are still many discordant elements, affecting sports training effect. Physical security awareness training is worse. The process is advancing quality education, therefore, most schools still maintained the traditional views and positions, that is very focused on the students' culture results of evaluation, often overlooked on the physical training of the students should have security education so that the safety of students protection awareness is very weak. Parents' irrational practices affect the popularity of security awareness. The only child of larger number, so that parents do not have rational thoughts affect physical training in safety awareness and establish. Strict parents blindly child's cultural lesson, rather than too many children participate in sports activities, to prevent children from being hit by injuries.

To avoid security incidents teacher, teaching becomes free. Life may be based on fear of security incidents, PE teachers often teach lessons allow students to move freely. Thus, the contact should students fail physical training, the quality of its performance standards will be doped fraudulent, not conducive to improving the quality of the students themselves, but also with the goal of quality education and farther away. Student Sports Training Church discipline is poor, lower their quality. Now students are mostly only child, spoiled by the parents. Thus, some students in sports training often do not obey the teacher's management, but also other students and peace cannot be friendly to each other, and sometimes lead to quarrel or fight, causing injury.

Physical education facilities are not complete, there is a security risk. The successful completion of physical training cannot do without high-quality sports equipment and teaching facilities. Currently, most high school physical education facilities aging, cannot be updated, there are many security risks, easily lead to teaching accident.

\section{The Approaches and Methods of Sports Teaching Security}

Faced with a lot of school sports injury, based on school sports safety awareness, we believe that security can take the following ways and means: 
Ground maintenance equipment sports venues teaching venues and equipment are closely related, shaking single parallel bars, uneven ground will become security risks in Physical Education and Sports Accidents caused thereby have to draw our attention. Therefore, the first class of teachers and school inspection regular maintenance and replacement work is of great significance. School should be a person or department responsible for this work, check for loose equipment installation and equipment parts are aging identify problems and timely maintenance. Before the event should also be grounds for inspection equipment, such as digging loose sand pit, flat runway, such as problem and cannot be repaired, it should be suspended. Ground maintenance is to eliminate the space, equipment damage caused by the accident the most effective way.

Warming proper arrangements are an essential part of Physical Education, which is the basis of physical education teaching, but also protect the safety of the teaching. PE teachers and students cannot muddle through preparatory activities, but cannot do the preparatory activities directly or teaching the game. Physical exercise on preparations inadequate, unreasonable content, may lead to security incidents. Warming arrangements should take into account the level of the student movement, physical condition, teaching contents and other factors, so the PE teachers should design suitable warm-up activities of this course, the movement of the injured area and ease the burden of large, should pay special attention to preparations. For example, run quickly to focus on the activities of the ankle, knee, hip and other joints as well as the front and rear thigh muscles. Targeted, adequate preparation is the key to effective prevention activities PE injuries and accidents.

Teaching and Training clever design is first, to do PE teachers venue arrangements. At the same time there are more than two classes in class, teachers should be coordinated with other classes, try to avoid conflict with the teaching content. For example, teaching soccer game and the possibility of throwing a medicine ball in space, the student was injured very substantial. Second, teachers must be reasonable arrangements for exercise stress. Pay special attention to the local burden of moving organs, to avoid exercise load exceeds the capacity of the students outside, prevention of injuries caused due to extremely weak. Furthermore, the physical education teachers in the organization should be reasonable.

Enhance the teaching ability of PE teachers are more dominant teaching, there is a certain danger for the content, the choice of teaching methods and means to be aware of, sports injuries before they happen. Do exercises auxiliary exercises to help students master the moves. Physical fitness and motor skills for poor students but also reduce the difficulty and to strengthen the protection and help to prevent injuries. PE teachers also need to continuously improve all aspects of capacity, especially for injuries foresight. Prone to accidents and have foresight to guard against, to understand under what circumstances prone to injury accidents, how to prevent it, and so on. Lesson problem may occur in a contingency plan, so as to take preventive measures.

Strict compliance with organizational discipline, good organization and discipline is to protect the safety of Physical Education. Physical education and diverse forms of student activities space, if not strictly require students to teachers, it is difficult to control the teaching process, it is prone to injuries. Therefore, teachers must be strict discipline, training students to obey orders and commands good habits, to impede the safe misconduct appearing in the classroom, such as frolicking, climbing crawling chaos, rough play, in violation of rules, PE teacher to be criticized strongly, causing the student's attention. Of the situation, teachers should be analyzed, take warning, avoid the pitfalls. So as to enable students' ideologically attention, prompting the students to form a high degree of safety awareness and prevent accidents. Physical Education Teaching Accidents is 
an objective reality, as long as we enhance security awareness and take proper teaching measures to strengthen teaching and student management will minimize the occurrence of sports injuries.

\section{Conclusion}

The Educational Reform objectively requires high school sports training should pay attention to safety awareness and establish and build a strong, in order to ensure the smooth development of sports teaching work to ensure the timely achievement of teaching objectives. Therefore, to establish security awareness training sports education in schools from the whole. In sports training school, to effectively establish a sense of security, students' self-help and resilience: pay attention to PE Teachers conceptual change and change and ethical improvement of teaching methods; with attention and student discipline parents of culture; focus on sports teaching facilities hazards excluded. In short, do a good job safety education in high school sports training is the demand of the times and social progress of the performance, is the proper meaning of quality education, the whole society should be of common concern and support.

\section{Reference}

[1] Miner Joshua L, Joe Bold.Outward Bound USA: Crew Not Passengers [M] Seattle:. The Mountaineers Books, 2002.

[2] Mackenzie, M. How are Adventure Education Program Outcomes Achieve the literature. Australian Journal of Outdoor Education, 5 (1), 2000.19-28.

[3] ERGER.A Continuous improvement and kaizen: standardization and organizational design [J] .Journal of Integrated Manufacturing Systems, 1997,8 (2): 110-117.

[4] Lessons in Danger:. School Safety and Security OECD Paris:. OECD, 2005. 